\title{
Correlation between Morphological Architecture of Rice Seed and Transmission of Fungal Pathogens
}

\author{
Arju Akter ${ }^{1^{*}}$, Md. Rasal-Monir ${ }^{2}$, Nabila Sultana Dola ${ }^{3}$, Meer Rifath Jahan Usha ${ }^{2}$ \\ and A. Q. M. Bazlur Rashid ${ }^{1}$ \\ ${ }^{1}$ Department of Plant Pathology, Bangladesh Agricultural University, Mymensingh, Bangladesh. \\ ${ }^{2}$ Department of Horticulture, Sher-e-Bangla Agricultural University, Dhaka, Bangladesh. \\ ${ }^{3}$ Department of Plant Pathology, Patuakhali Science and Technology University, Dumki, Patuakhali,
}

Bangladesh.

Authors' contributions

This work was carried out in collaboration among all authors. Authors AA, MRM and AQMBR designed the study, performed the statistical analysis, wrote the protocol and wrote the first draft of the manuscript. Authors MRM and MRJU managed the analyses of the study. Authors AA, MRM and NSD managed the literature searches. All authors read and approved the final manuscript.

Article Information

DOI: 10.9734/ARRB/2019/v33i430128 Editor(s):

(1) Paola Angelini, Department of Applied Biology, University of Perugia, Perugia, Italy.

(1) R. K. Lal, CSIR-CIMAP, India.

(2) Delian Elena, University of Agronomical Sciences and Veterinary Medicine from Bucharest, Romania. Complete Peer review History: http://www.sdiarticle4.com/review-history/52243

Original Research Article

Received 06 August 2019

Accepted 16 October 2019

Published 28 October 2019

\begin{abstract}
A total of ten rice (Oryza sativa L) seed samples of variety BR 28 were collected from the farmers of (Salakandi, Boira) Mymensingh, Bangladesh. Prevalence of fungi was recorded as Bipolaris oryzae, Fusarium oxysporum and Fusarium moniliforme, through blotter test. Statistically B. oryzae was recorded as the highest prevalent fungus in all the seed samples of various architectural categories of seeds such as large (14.5\%), medium $(9.5 \%)$, small $(11.5 \%)$ followed by $(14.5 \%)$ and $(4.5 \%)$, respectively in shriveled and chaffy seeds. While in large, medium and small seeds $F$. moniliforme was recorded significantly as the least prevalent pathogen. The effect of colour on the transmission of $B$. oryzae was recorded as the highest in number in case of bright seeds (8.5\%) and spotted seeds (dark brown) (17.5\%). The effect of smooth and rough surface on the prevalence of fungal pathogen $B$. oryzae was recorded as the highest in number in case of awnned seed $(21.5 \%)$, smooth surface $(12.25 \%)$ and rough surface seeds $(18.5 \%)$. The regression equations of the fungal pathogens indicate that the morphological architecture of the seeds shape \& size, colour and
\end{abstract}

*Corresponding author: E-mail: aakter006@gmail.com; 
smooth and roughness significantly correlated with the transmission of pathogens Statistically, the highest germination of seeds was recorded in the medium sized (83.5\%). The highest germination of seed was recorded in the spotted seed (69.5\%). The minimum germination of seed was recorded in the bright colour seed. The highest germination of seed was recorded in the awnned seed $(59.5 \%)$ followed by smooth surface $(37.5 \%)$ and rough surface $(53.5 \%)$. These results obviously indicate the tangible effect of the seed architecture at the transmission of the fungal pathogens affecting the planting value as well as germination of the rice seeds.

Keywords: Rice; seed; correlations; fungal diseases.

\section{INTRODUCTION}

Rice (Oryza sativa L.) is an important cereal crop consumed exclusively by humans. It feeds more than $50 \%$ of the world's population and is one of the most important crops in the world [1]. It is one of the major sources of calories for a large percentage of the world population, particularly in Asia [2]. Bangladesh is predominantly an agriculture based country with more than 164.4 million living on 14.84 million hectares of land [3]. The population is expected to increase, by the year 2050, around 200 million [3]. Rice and wheat are the main food grains of Bangladesh. Rice alone constitutes the lion share $(96 \%)$ of the total food grain produced in the country [4].

Seed is the most important input for crop production. Pathogen free healthy seed is crying need for desired plant populations and good harvest. Many plant pathogens are seed-borne, which can cause enormous crop losses. Coincidentally, the most important or devastating crop diseases are seed-borne and caused by fungi. It has also been demonstrated that seedborne fungi are responsible for poor health of seeds in many crops [5]. The low productivity is attributed to a number of factors, important of which are seed-borne diseases, causing up to $50-80 \%$ yield losses depending on the crop susceptibility, disease severity and agro ecology [6].

In Bangladesh, out of $16 \%$ annual crop losses due to plant diseases, at least $10 \%$ loss is incurred due to seed-borne diseases [7]. Rice suffers from 17 different seed-borne diseases and of these 11 seed transmitted fungal pathogens are responsible for causing disease in rice [8]. Many Seed -borne pathogens have worldwide distribution and under favorable conditions may cause diseases in epidemic form. Seed -borne diseases create a great threat to the production of crops in Bangladesh. As many as 490 Seed -borne diseases are known to attack 756 different crop plants in Bangladesh of which at least 200 are of major concern [9].

Morphology of seed is the study of forms and structure of a seed consisting mainly its shape, size and colour. Seed morphology includes the shape and size, the important characters of the seed quality, [10]. Morphologically abnormal seeds may also give rise to the higher level of seed transmission of more virulent pathogen, compare to the normal seeds. Colour also may play an important role in transmission of the pathogen.

The architecture of the seed involving design, roughness or smoothness, presence of hairy structures such as seed hairs, awns, the funicle, location of the microphyle, hilum etc. may be considered as the architecture of seed which may have a profound effect on the transmission of seed-borne pathogens. But, information on such area is lacking. Therefore, the present piece of work was undertaken to determine the association of seed borne fungal pathogens, explore the impact on the planting value of the seeds and determine the correlation between fungal association of the seeds and impact on the germination of the seeds.

\section{MATERIALS AND METHODS}

\subsection{Experimental Site}

The experiment was carried out in the MS laboratory of the Department of Plant Pathology, Plant Disease Clinic and Seed Pathology centre (SPC) of Bangladesh Agricultural University (BAU).

\subsection{Collection of Seed}

Rice seeds of the variety BR 28 were collected from the farmers of Mymensingh (Salakandi, Boira), Bangladesh. 


\subsection{Architectural Categorization of the Collected Seeds}

From the working samples 100 seeds were taken from each category and were used for sorting according to their various architectural characteristics such as described below [3].

Shape and Size (large, medium, small, shriveled, chaffy).

\subsubsection{Large seeds}

In according to Bangladesh Agricultural Development Corporation (BADC), the seeds which are above $2.25 \mathrm{~mm}$ in size and consist in a normal embryo, uniform natural bright color, seed hairs and smooth surface have been designated as large seeds. Outer layer of this category of seeds is intact.

\subsubsection{Medium seeds}

This category of seeds possessed high vigor and almost all the characteristics described in case of large seeds except above and belong $2.25 \mathrm{~mm}$.

\subsubsection{Small seeds}

This category of seeds possessed high vigor and almost all the characteristics described in case of large seeds except the size, which is below 2.25 $\mathrm{mm}$.

\subsubsection{Shriveled seeds}

Seeds of variable sizes and shapes, usually deformed and discolored in there structure and texture, with rough and wrinkled external surface are termed as shriveled seeds. The embryonic region is almost deformed and seed hair is found scattered with blackish in colour. The seeds are usually small, narrow and lighter in weight.

\subsubsection{Chaffy seeds}

Chaffy seeds are the dry, scaly protective casings of the seeds. Chaff is inedible for humans, but livestock can eat it and in agriculture it is used as livestock fodder, or is a waste material ploughed into the soil or burnt.

\subsubsection{Bright color seeds}

Seed colour is a simple and excellent indicator of seed quality [11]. Dharamalingam and Basu [12] in green gram indicated that off colored seeds were poorer in quality, while Srimathi [13] identified that seed coat colour was an indicator of seed maturation in a few tree species. Seeds with bright color without brown to dark brown spot are call bright color seed.

\subsubsection{Discolored seeds}

The seed borne inoculum of Alternaria alternata (responsible for ash grey discolouration) and Helminthosporium oryzae (responsible for black discolouration, dark purple discolouration, dark brown spots and light to dark brown dot like spots) were found in seed coat and endosperm of discoloured seeds whereas fungi, namely, Curvularia geniculata, C. lunata (responsible for eye shape spot), Fusarium equiseti, $F$. graminearum, F. rnoniliforme (responsible for light pink discolouration) and Sarocladium oryzae (responsible for light brown discolouration) were found in seed coat, endosperm and embryo of discoloured seeds.

\subsubsection{Spotted seeds}

Seeds with small dark brown spots are considered as spotted seed. Spotting caused by certain diseases (brown spot) or insect (rice bug feeding damage).

\subsubsection{Rough surface seeds}

The ripened ovary and its associated structures such as the lemma, palea, rachilla, sterile lemmas, and the awn if present. Sterile or underdeveloped ovaries enveloped by a welldeveloped lemma and palea should be termed empty or under-developed spikelets.

\subsubsection{Smooth surface seeds}

Smooth means having a relatively even and regular surface; free from perceptible projections, lumps, indentations, and roughness and not wrinkled, pitted, scored, or hairy and without waves or undulations.

\subsubsection{Awnned seeds}

One of the slender bristles that terminate the glumes of the spikelet in some grasses, including cereals.

\subsection{Detection of Seed Borne Fungi}

Fungi associated with the seeds in different samples were detected by following blotter incubation method [3]. Four hundred seeds from each sample of cultivar were examined by 
placing them on three layered moist blotter paper (Whatman No.1) in $9 \mathrm{~cm}$ diameter plastic Petridishes. Twenty five seeds from the working sample drown by spoon method from the thoroughly mixed sample were placed in each Petridish and incubated at $25 \pm^{\circ} \mathrm{C}$ under 12 hour's cycle alternate Near Ultra Violet (NUV) light and darkness. After 8 days of incubation, the seed were examined under stereo-binocular microscope with 25 to $50 \mathrm{X}$ magnifications for the seed borne fungi, particularly for the characteristic growth of Bipolaris oryzae [14]. In doubtful cases temporary slides were prepared from the fungal colony and observed under compound microscope. Appropriate Keys were consulted for identification of the fungi $[14,15]$. The results were expressed as percent incidence.

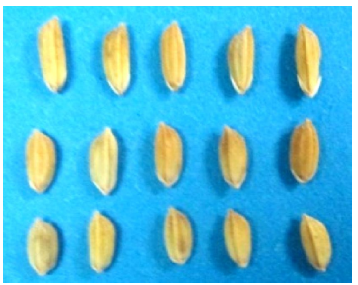

Fig. 1.1. Large (top) medium (middle) and small (bottom) seed

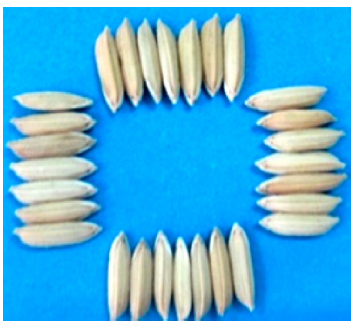

Fig. 2.1. Bright colour seed

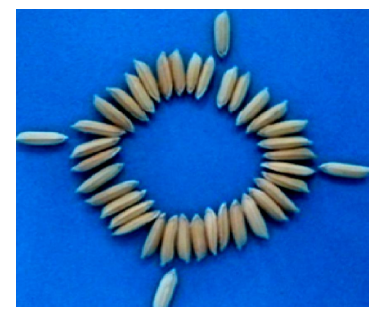

Fig. 3.1. Smooth surface seed

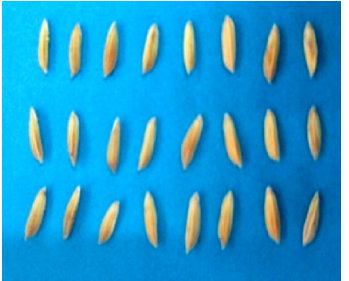

Fig. 1.2. Shriveled seed

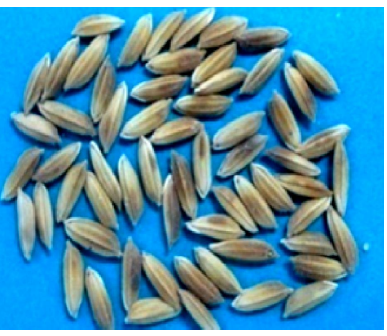

Fig. 2.2. Discoloured seed

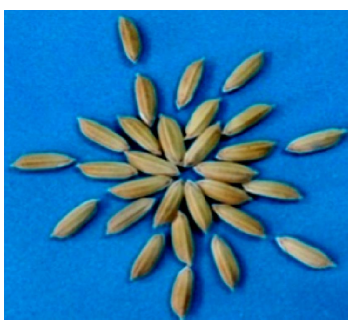

Fig. 3.2. Rough surface seed

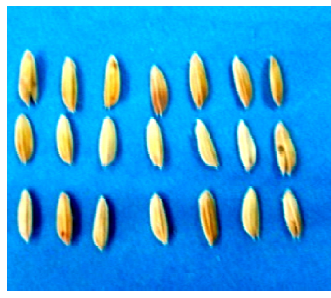

Fig. 1.3. Chaffy seed

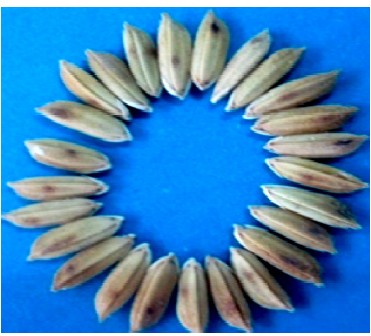

Fig. 2.3. Spotted seed

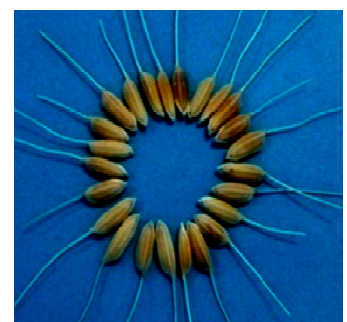

Fig. 3.3. Awnned seed 


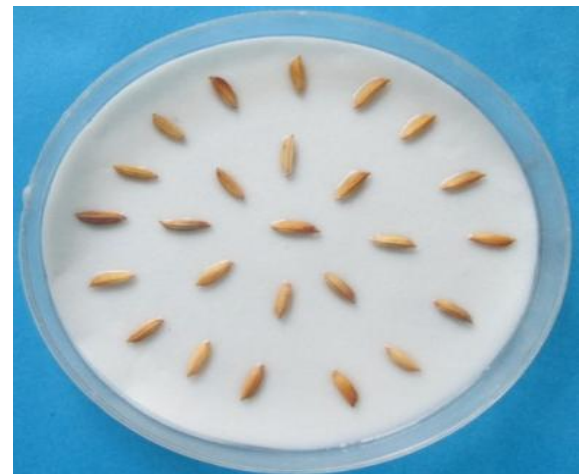

Fig. 4. Seed health test by blotter method

The seed samples tested in moist blotter for there to detect transmission of the borne pathogens (Fig. 4).

Prevalence of the seed borne fungal pathogen was recorded separately as born by their respective architectural host. Three major fungal pathogens namely Bipolaris oryzae (cause of brown spot), Fusarium oxysporum (cause of Foot rot) and Fusarium moniliforme (cause of bakanae) were recorded in different architectural seed samples.

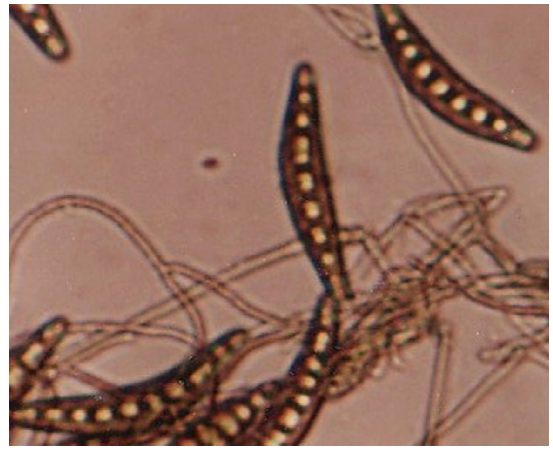

Fig. 5. Structure of Bipolaris oryzae

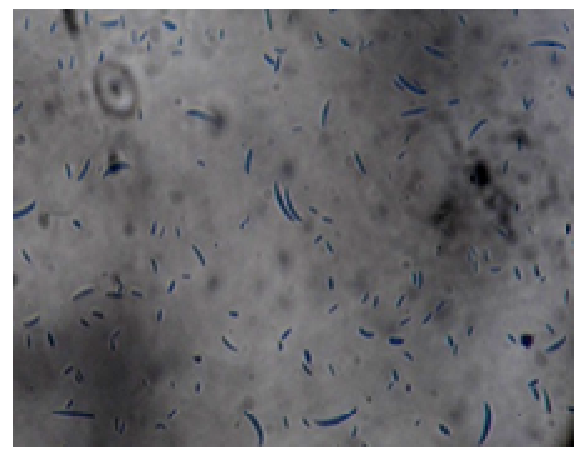

Fig. 6. Structure of Fusarium moniliforme

\subsection{Seed Shape and Size}

Statistically $B$. oryzae was recorded as the highest prevalent fungus in all the seed samples of various architectural category such as large seeds $(14.5 \%)$, medium seeds $(9.5 \%)$, small seeds $(11.5 \%)$, followed by shriveled seeds $(14.5 \%)$ and chaffy seeds (4.5\%), respectively. $B$. oryzae was recorded statistically the highest in number in all category of large, medium, small, shriveled and chaffy seeds (Fig. 8).

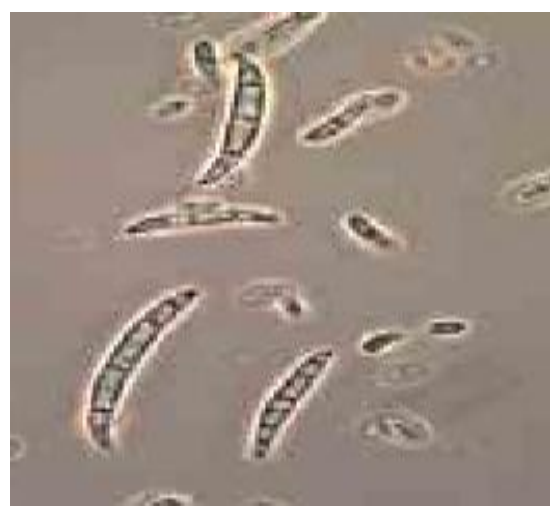

Fig. 7. Structure of Fusarium oxysporum

The same result was followed by $F$. oxysporum in all categories of seeds but $F$. moniliforme was prevalent in shriveled and chaffy seeds only. While in large medium and small seeds $F$. moniliforme was recorded significantly as the least prevalent pathogen (Fig. 8).

Relationship between shape and size of seeds and transmission of fungal pathogen through the category of (shape and size) of seeds have been shown in Fig. 9 with the regression equation of $y=-1.5 x+15.4$ (B. oryzae), $y=-0.8 x+8.95(F$. oxysporum) and $\mathrm{y}=0.4 \mathrm{x}+1.6$ ( $F$. moniliforme).

The regression equations of the three fungal pathogens indicate that the morphological architecture of the seeds such as shape \& size significantly correlated with the transmission of pathogens. ( $B$. oryzae) is resulted negatively correlation with the shape and size of seeds ( $y=$ $-1.5 x+15.4)(r=0.57)$. It is revealed from the figure that with the per unit increase of transmission of $B$. oryzae there is a decrease of the architectural category, i.e. significantly highest transmission of the pathogen was recorded in large category of seeds $r=0.6$ followed by the chaffy seeds as the least. The similar trend of correlation due to ( $F$. oxysporum) 
has been recorded with the regression equations $y=-0.8 x+8.95(r=0.7)$.

But increase of transmission of $F$. moniliforme reverse response of morphological seed architecture was recorded with the regression equations $y=0.4 x+1.6(r=0.2)$. It indicates that the pathogen destructively might change the architectural shape and size of the seeds leading to the chaffy (non seed).

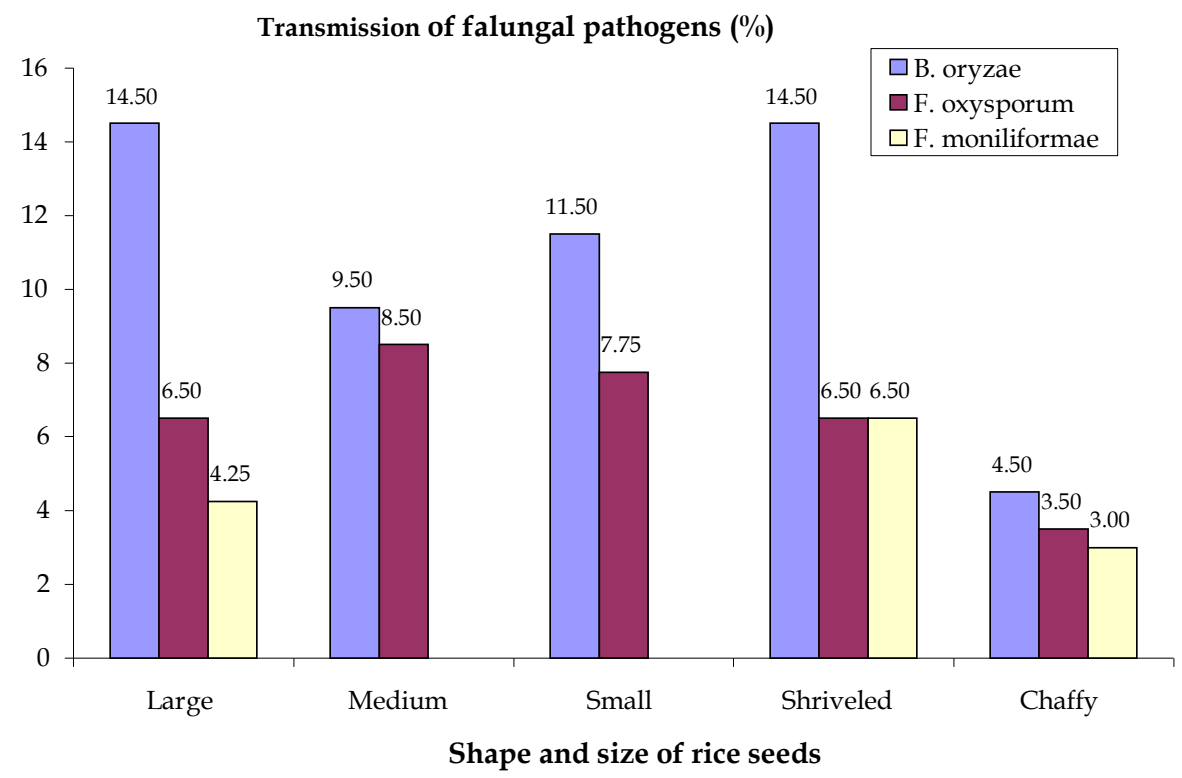

Fig. 8. Transmission of seed borne fungal pathogens through various shape and size of rice seeds

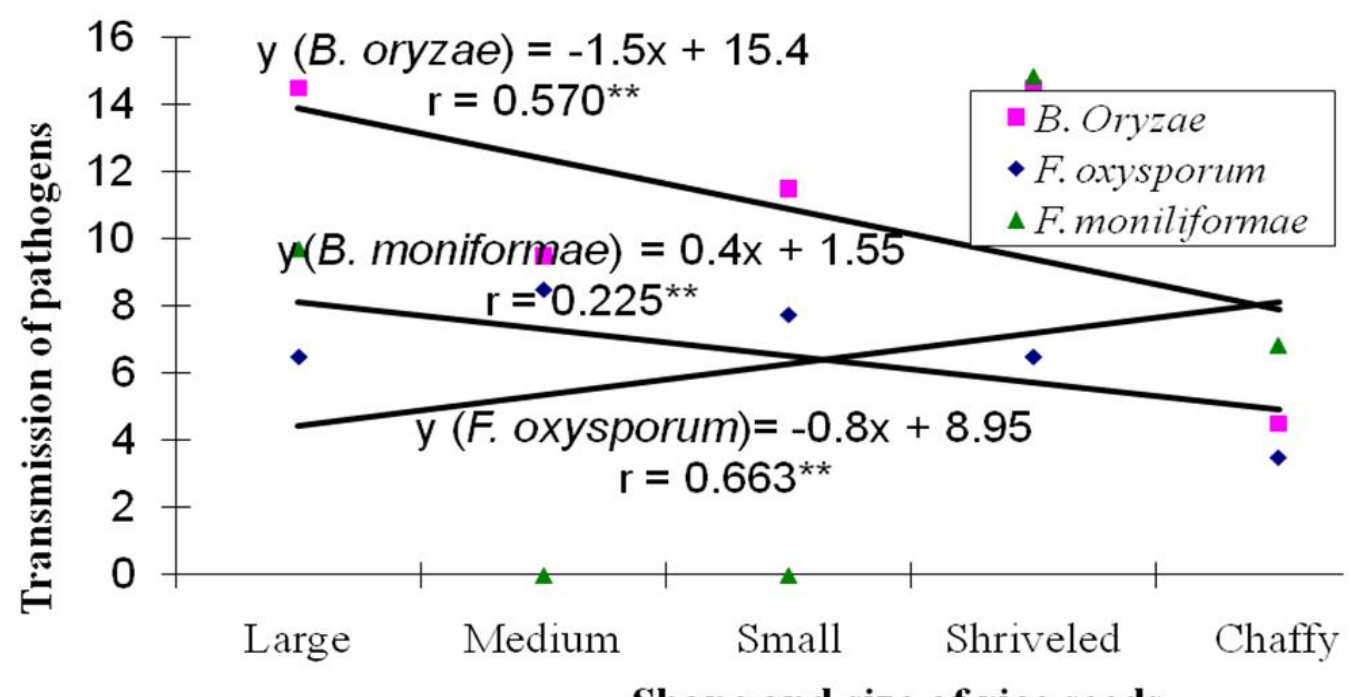

Shape and size of rice seeds

Fig. 9. Correlation between transmission of fungal pathogens and morphological architecture of rice seeds 


\subsection{Seed Colour}

It is revealed from the Fig. 10 that the effect of colour on the prevelnce of fungal pathogens $B$. oryzae was recorded as the highest in number in case of bright seeds (8.5\%) and spotted seeds (dark brown) (17.5\%). The same result was recorded in case of discolored seed (brown) (15.5\%). Bothfungi (B. oryzae and $F$. oxysporum) were recorded as the secondhighest in discolored (B. oryzae) and bright (6.5\%)andspotted (dark brown) seed (8.5\%). F. oxysporumfungus was recorded as the secondhighest. Number of $F$. moniliforme was recorded in any of the architectural category of seeds.

Relationship between colour of the seeds and transmission of fungal pathogen through the category of (colour) of seeds is shown in Fig. 11 with the regression equation of $y=4.5 x+4.2$ ( $B$. oryzae), $y=x+8.1667(F$. oxysporum).

The regression equations of the two fungal pathogens indicate that the morphological architecture of the seeds such as colour significantly correlated with the transmission of pathogens. ( $B$. oryzae) is recorded positively correlated with thecolour of seeds $(y=4.5 x+4.2)$ $(0.9)$. It is revealed from the figure that with the per unit increase of transmission of $B$. oryzae there is decrease of the architectural category, i.e. significantly highest transmission of the pathogen was recorded in spotted category of seeds with $r=0.9$ followed by the bright colour seeds as the least. The similar trend of correlation due to ( $F$. oxysporum ) was recorded with the regression equations $y=x+8.7(r=0.2)$.

It indicates that the pathogen might change the architectural colour of the seeds leading to the spotted seed.

\subsection{Smooth and Rough Surface of Seed}

It is revealed from the (Fig. 12) that the effect of smooth and rough surface on the prevalence of fungal pathogen $B$. oryzae was recorded as the highest in number in case of awnned seed $(21.5 \%)$, smooth surface $(12.25 \%)$ and rough surface $(18.5 \%)$. The same result was recorded as the highest in number in case of awnned seed $(21.5 \%)$, smooth surface seed $(12.25 \%)$ and rough surface seed (18.5\%). Number of $F$. moniliformae was recorded in any of the architectural category of seeds.

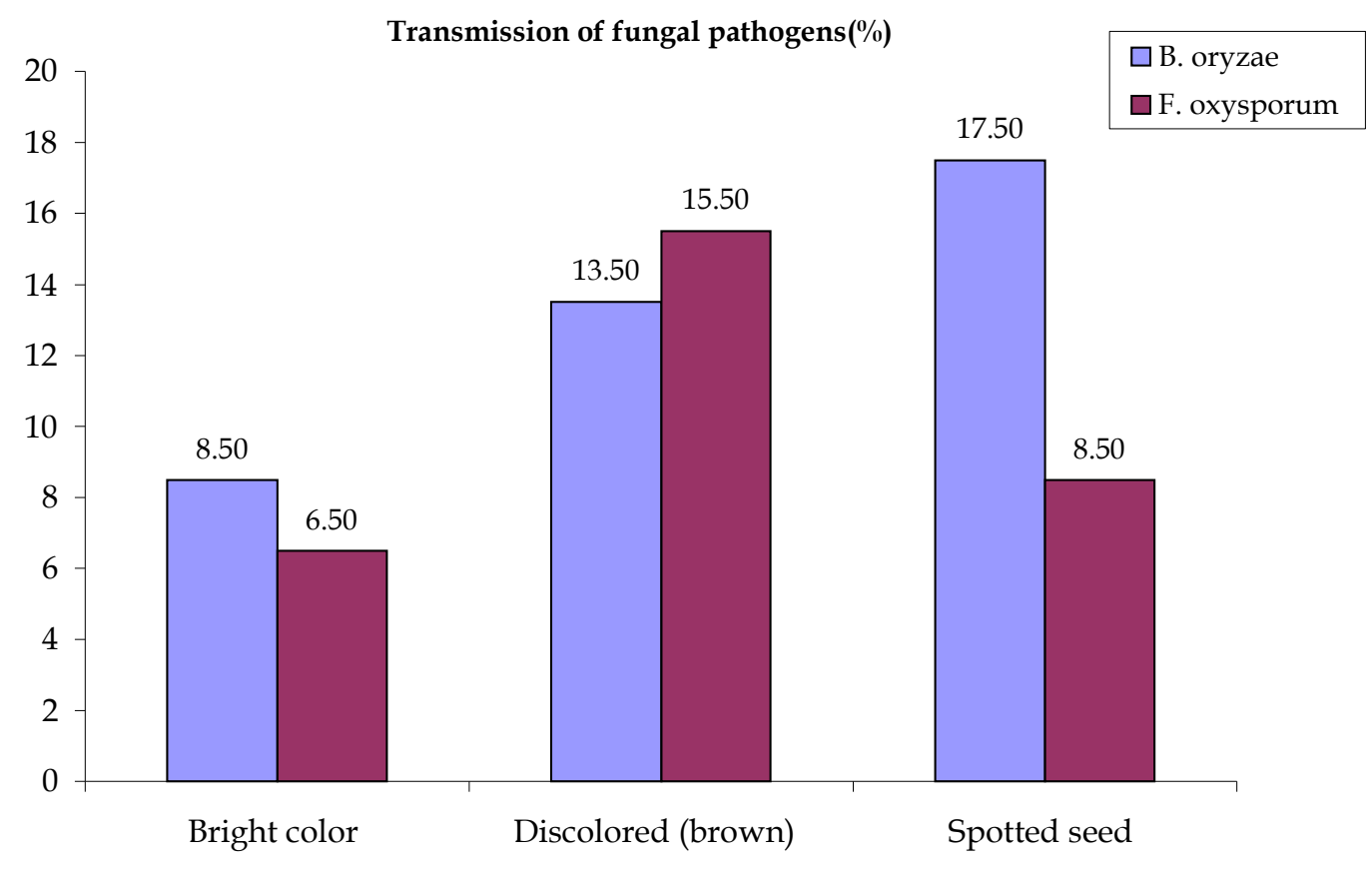

Colour of rice seeds

Fig. 10. Transmission of seed borne fungal pathogens through various colour of rice seeds 


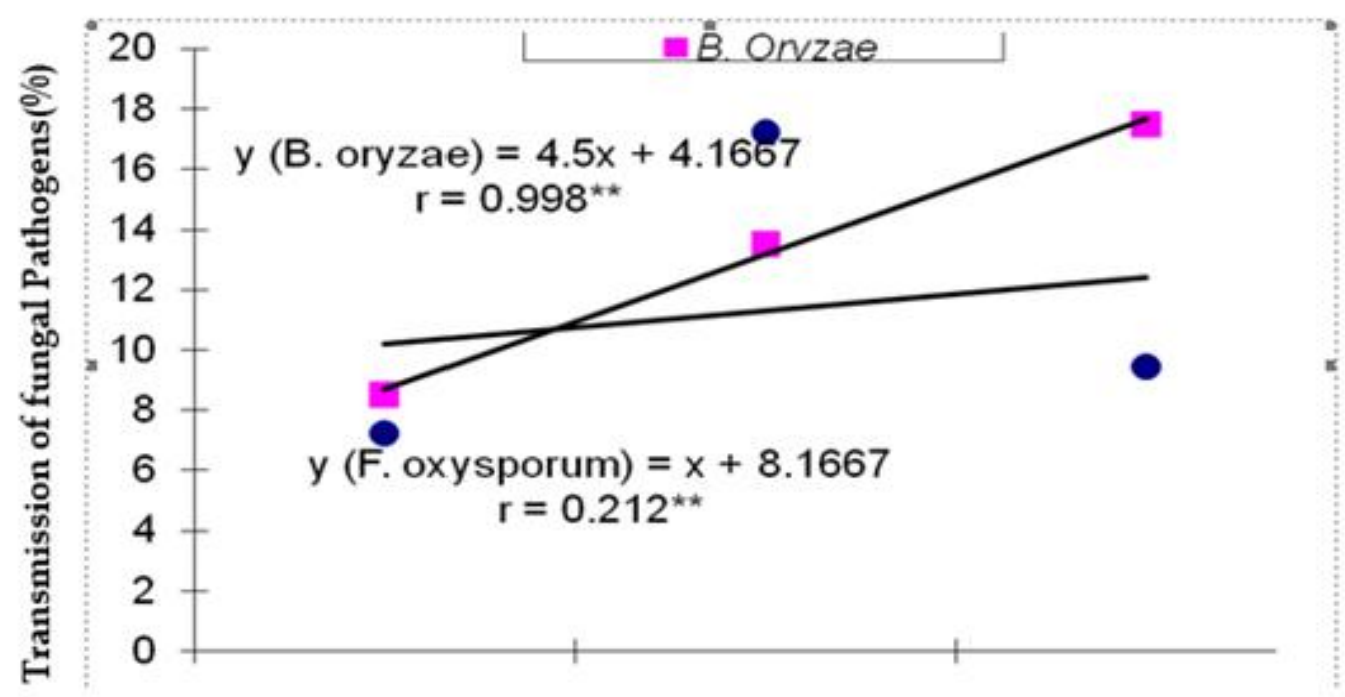

Bright seed Discolor seed Spotted seed

Fig. 11. Correlation between transmission of fungal pathogens and morphological architecture of rice seeds

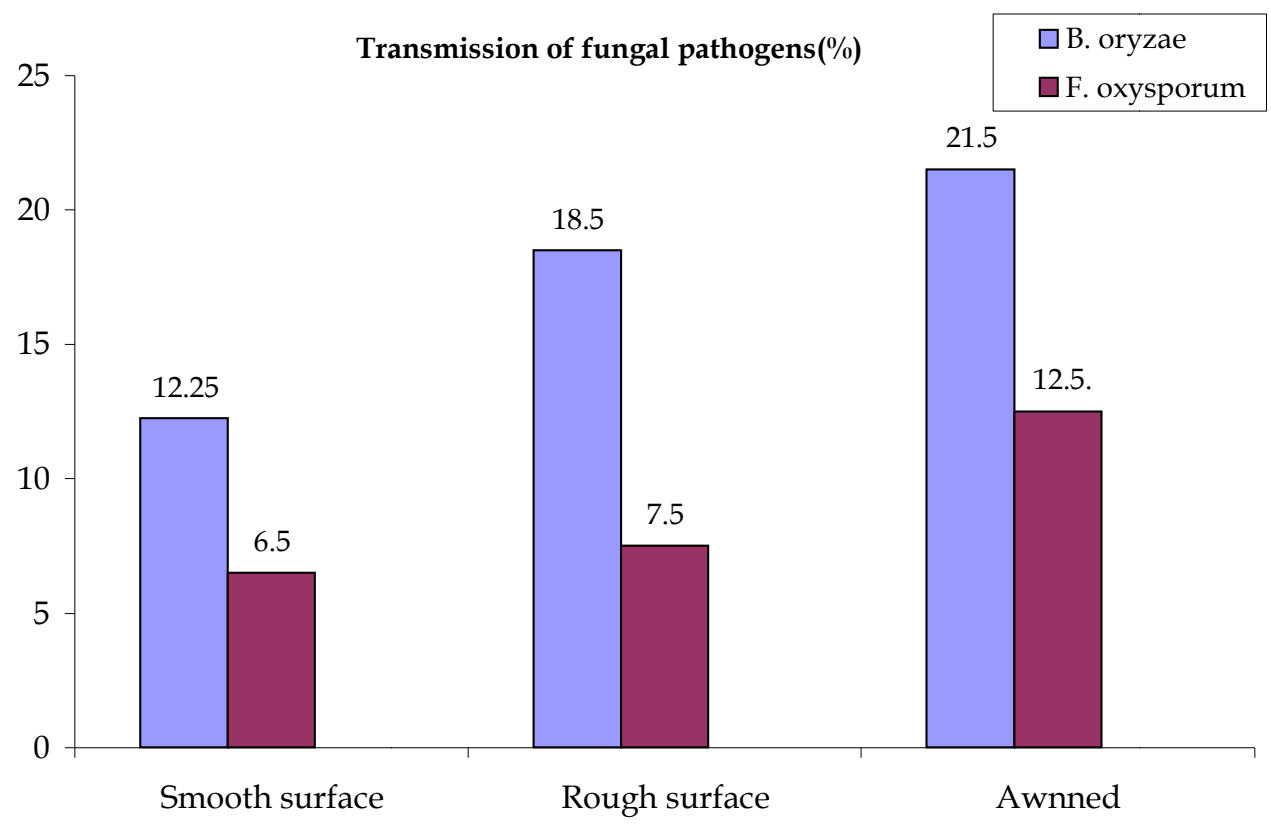

Smooth and rough surface of rice seeds

Fig. 12. Transmission of seed borne fungal pathogens through various smooth and rough surfaces of rice seeds 
Relationship between smooth and roughness of seeds and transmission of fungal pathogen through the category of (smooth and rough surface) of seeds have been shown in Fig. 13 with the regression equation of $y=4.625 x+8.166$ (B. oryzae), $y=3 x+2.8333$ (F. oxysporum).

The regression equations of the two fungal pathogens indicate that the morphological architecture of the seeds such as smoothness and roughness significantly correlated with the transmission of pathogens. (B. oryzae) is recorded positively correlated with the smooth and rough surface of seeds $(y=4.625 x+8.166)$. It is revealed from the figure that with the per unit increase of transmission of $B$. oryzae there is decrease of the architectural category, i.e. significantly highest transmission of the pathogen was recorded in awnned category of seeds $r=0.98$ followed by the smooth surface seeds as the least. The similar trend of correlation due to ( $F$. oxysporum ) with the regression equations $y=$ $3 x+2.8333 \quad(r=0.93)$.

It indicates that the pathogen might change the architectural smooth and rough surface of the seeds leading to the awnned seed.

\subsection{Effect of Seed Shape and Size on Germination}

Statistically the highest germination of seed was recorded in the medium sized $(83.5 \%)$ seed followed by large $(50.5 \%)$ and small sized $(51.5 \%)$ seed. The minimum germination of seed was recorded in the shriveled $(22.5 \%)$ seed and there was no germination in chaffy seed (Fig. 15).

Relationship between germination and transmission of fungal pathogen through the category of (shape and size) of seeds have been shown in Fig. 15 with the regression equation of $y=-11.6 x+81$. It is revealed from the figure that with 81 unit increase of seed to plant transmitting pathogen there is a unit decrease of the seed germination. The straight line evidences that the rate of decreasing trend of germination percentages of category (shape and size of seed) due to gradual increase of transmission of pathogen.

\subsection{Effect of Seed Colour on Germination}

Significantly the highest germination of seed was recorded in the spotted $(69.50 \%)$ seed followed by discolored $(59.50 \%)$ and bright seed $(34.50 \%)$. The minimum germination of seed was recorded in the bright colour seed (Fig. 16). Relationship between germination and transmission of fungal pathogen through the category (colour) of seeds is shown in Fig.17 with the regression equation of $y=15.5 x+24.83$. It is revealed from the figure that with 24 unit increase of seed to plant transmitting pathogen there is a unit decrease of the seed germination. The straight line evidences that the rate of decreasing trend of germination percentages of category (colour) of seeds of seeds due to gradual increase of transmission of pathogen.

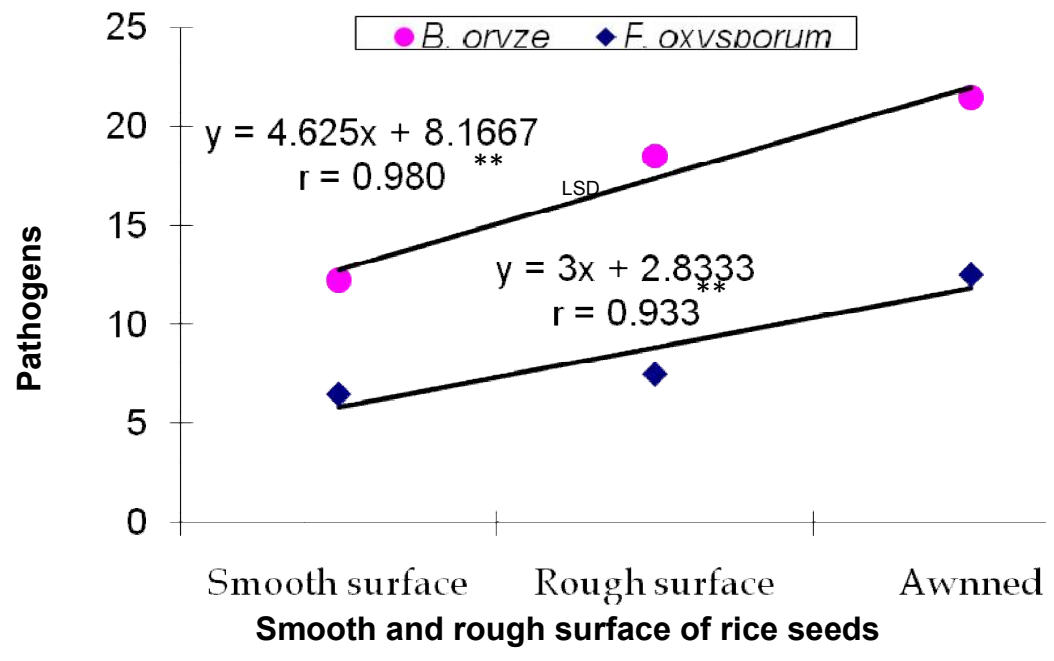

Fig. 13. Correlation between transmission of fungal pathogens and morphological architecture of rice seeds 


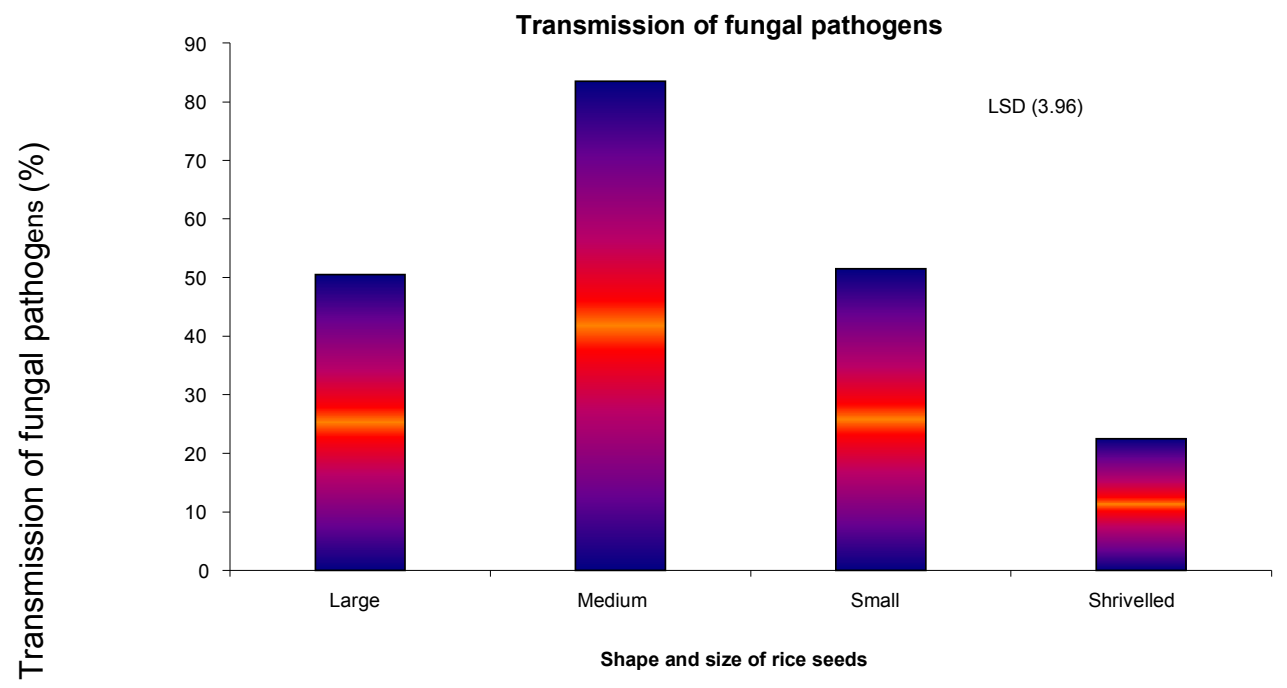

Fig. 14. Effect of seed borne fungal pathogens on the germination of different categories of rice seeds (Shape and size)

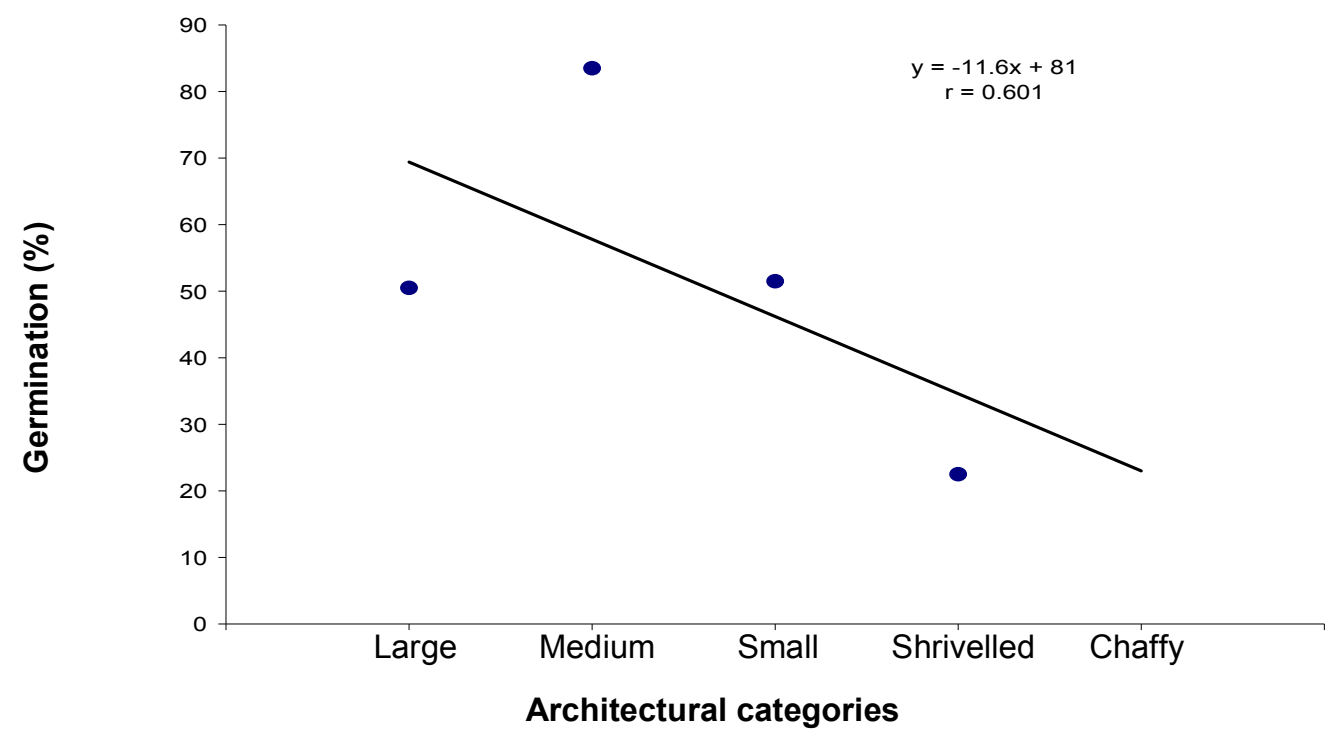

Fig. 15. Correlation between transmission of fungal pathogens and germination of different categories of rice seeds

\subsection{Effect of Seed Smoothness and Roughness on Germination}

It is revealed from the (Fig. 18) that the highest germination of seed was recorded in the awnned seed $(56.50 \%)$ followed by smooth surface $(36.50 \%)$ and rough surface seed $(55.50 \%)$. The minimum germination of seed was recorded in the smooth surface seed.
Relationship between germination and transmission of fungal pathogen through the category (smoothness and roughness) of seeds is shown in Fig. 19 with the regression equation of $y=11 x+28.17$. It is revealed from the figure that with 24.17 unit increase of seed to plant transmitting pathogen there is a unit decrease of the seed germination. The straight line evidences that the rate of decreasing trend of 
germination percentages of category due to gradual increase of transmission of (smoothness and roughness) of seeds of seeds pathogen.

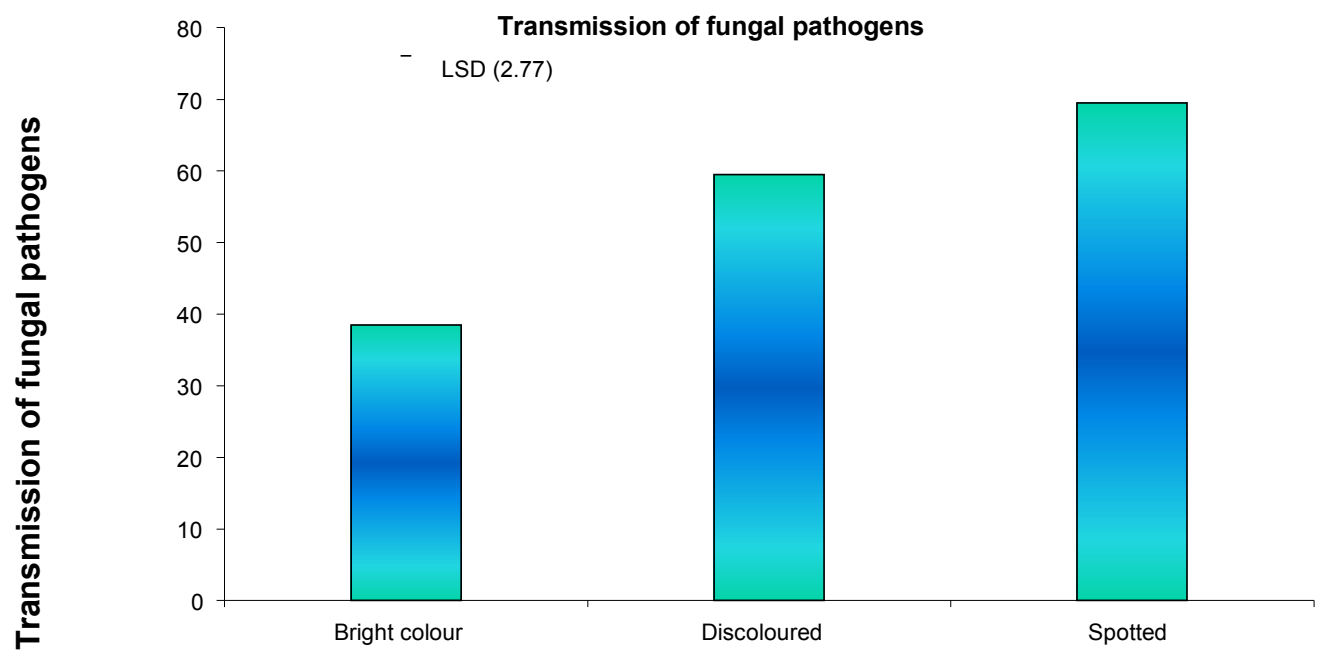

Colour of rice seeds

Fig.16. Effect of seed borne fungal pathogens on the germination of different categories of rice seeds (colour)

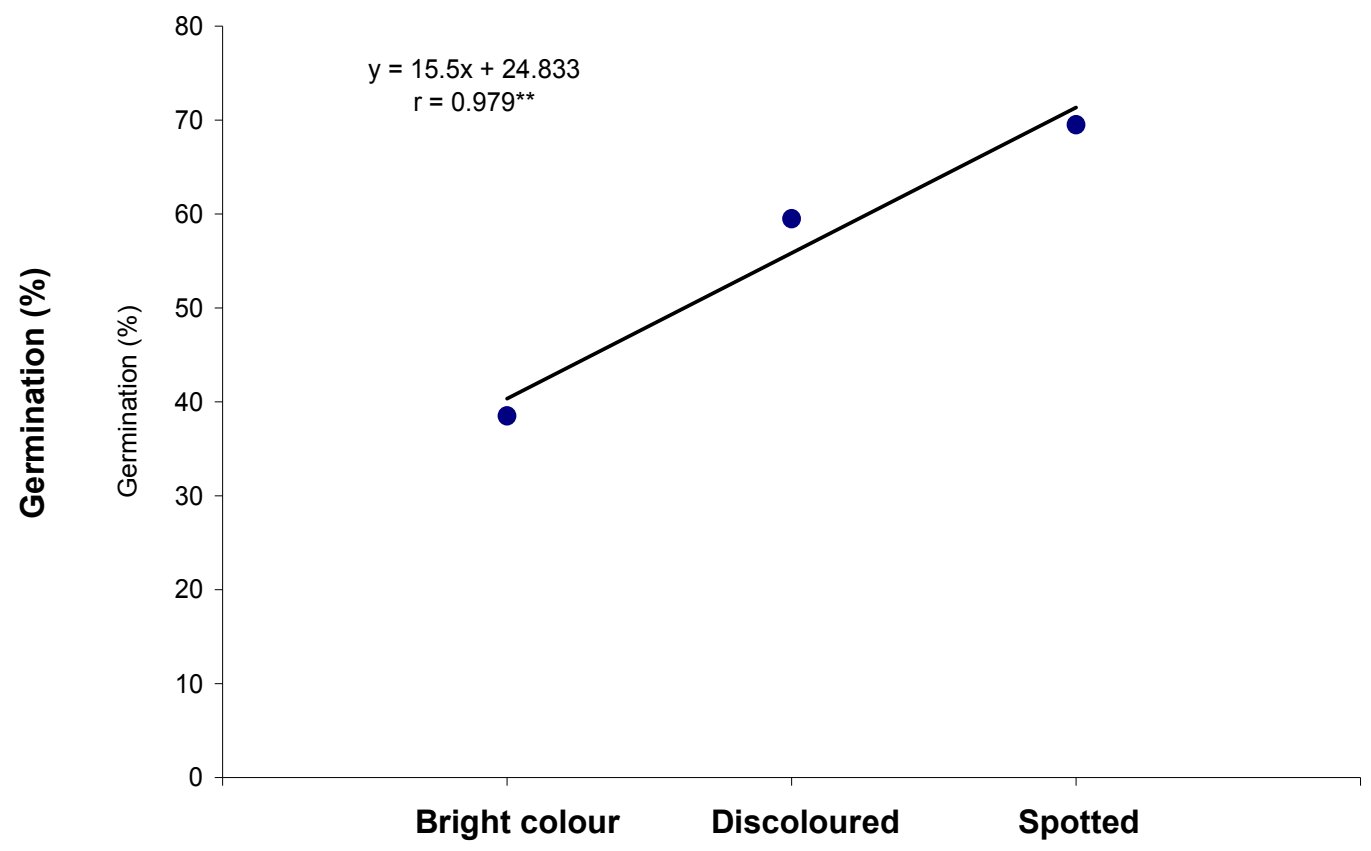

Fig. 17. Correlation between transmission of fungal pathogens and germination of different categories of rice seeds 


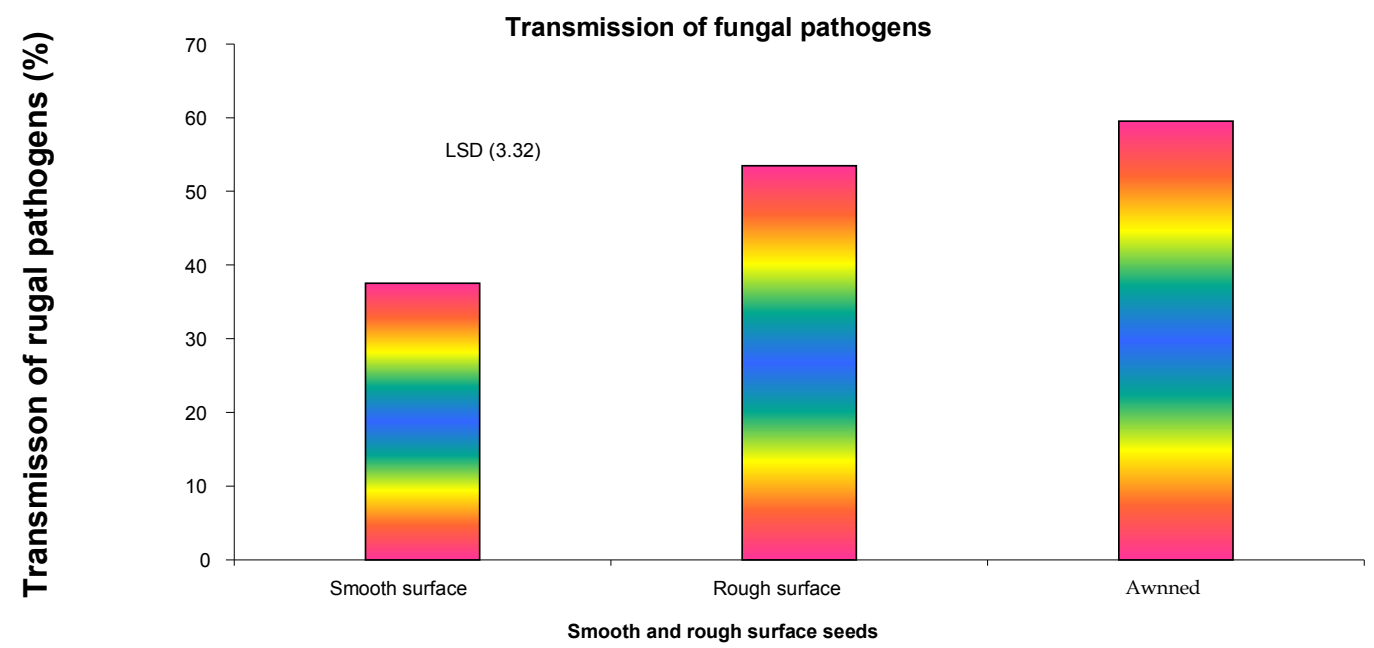

Fig. 18. Effect of seed borne fungal pathogens on the germination of different categories of rice seeds (smooth and rough surface)

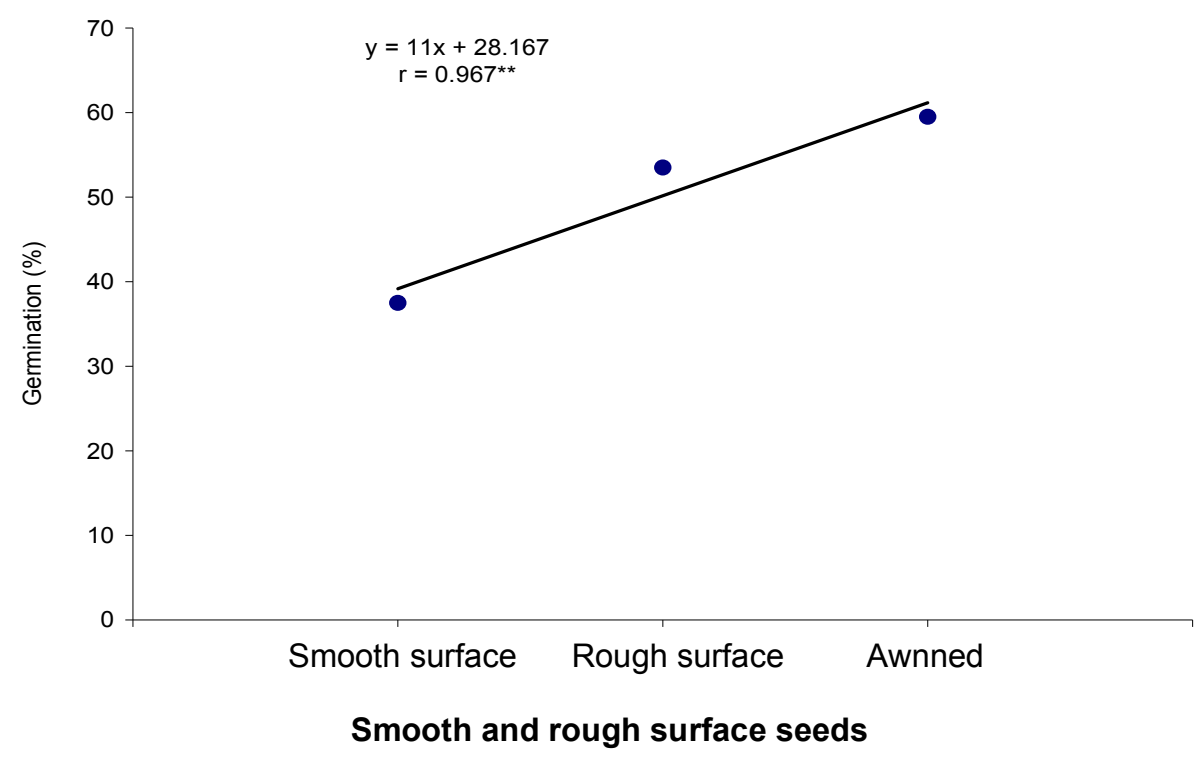

Fig. 19. Correlation between transmission of fungal pathogens and germination of different categories of rice seeds

\section{CONCLUSIONS}

The present study obviously reports that the variability in architectural forms of structure of seeds such as shape and size (large, medium, small, shriveled and chaffy), colour (bright colour seed, discolor seed, spotted seed) and roughness/smoothness (awnned, smooth, rough) may not only due to genetic but mostly due to the borne pathogens which can affect the seed quality as well as planting value of the seeds.
Therefore, while selecting the seeds of any variety of rice for sowing the criteria of the architectural form should be taken into consideration. Therefore, (i) The admixture of architectural variations in a seed sample may be assumed as the contamination by the seed borne pathogens. (ii) While selecting the seeds of any variety of rice for sowing the criteria of the morphological architecture should be taken into consideration. (iii) In such cases seed test must be followed properly. 


\section{COMPETING INTERESTS}

Authors have declared that no competing interests exist.

\section{REFERENCES}

1. Zhang $P$, Li J, Li $X$, Liu $X$, Zhao $X$. Population structure and genetic diversity in a rice core collection (Oryza sativa L.) Investigated with SSR Markers. PLoS One. 2011;6(12):27565.

2. Datta SK. Principle and practice of rice production. John Wiley \& Sons, New York; 1981. Deka B, Ali MS. Rice grain fungi occurrence and role over storage seed. Plant Health. 1995;1:26-28.

3. Anonymous. Statistical year book of Bangladesh, Bangladesh Bureau of Statistics. Ministry of Planning, Dhaka, Bangladesh; 2009.

4. Anonymous. Population reference Bureau estimates and projections; And UN Population Division, World Population Prospects: The 2008 Revision; 2009a.

5. Neergaard P. Seed pathology 1. The Macmillian Press Ltd. 1979;839. Negi AK, Todaria NP. Effect of seed size and weight on germination pattern and seedling development of some multipurpose tree species of Garhwal Himalaya. Indian For. 1997;123:32-36.

6. Raymundo SA. Diseases of rice in Siera Leone. Technical. Bulletin. 4, Rice. Research Station, Rokupr, Sierra Leone, West Africa. 1980;34.

7. Fakir GA. Teaching, research and training activities on seed pathology in Bangladesh. Seed Science and Technolog. 1983;11:1345-1352.

8. Fakir GA. Anannotated list of seed borne disease in Bangladesh Agricultural
Information Service, Ministry of Agriculture Complex, Dhaka. 1982;15-17.

9. Fakir GA, Islam MR, Islam MF. Survey on the health status of jute and rice seeds of farmers of farmers of Sadar Thana, Mymensingh. BAU Research Programm. 1990;4:42-47.

10. Bazlur Rashid AQM, Fakir. SPL research report on the survey of bipolaris leaf blight epidemic in Bangladesh. Seed Pathology Laborotory, Department of Plant Pathology, BAU, Mymensingh; 2000.

11. Oliver WW. Influence of seed coat colour on seed quality of rice bean (Vigna umbellata). Department of Seed Science and Technology Tamil Nadu Agricultural University, Coimbatore - 641 003, Indian Agricultural Science Digest. 1994;22(4): 249-251.

12. Dharamalingam C, Basu RN. Influence of seed coat colour on seed quality of rice bean (Vigna umbellata). Department of Seed Science and Technology Tamil Nadu Agricultural University, Coimbatore - 641 003, Indian Agriculture Science Digest. 1993;22(4):249-251.

13. Srimathi P. Ph.D. Thesis, Tamil Nadu Agricultural University, Coimbatore; 1997. Talukder $\mathrm{MH}$, Mathur SB, Veena MS, Mortensen CN. Effect of manual cleaning on health and germination of rice seeds. Seed Science and Tecnology. 2004;32(2): 405-415.

14. Chidambram $P$, Mathur SB, Neergaard $P$. Identification of seed-borne Drechslera species. Friesia. 1973;10:165-207.

15. Booth C. The genus Fusarium. CMI, Kew, Surrey, England. 1971;238. Chai RY, Jin $M Z$, Zhang QS. The inhabiting fungi of discoloured paddy rice grains and their pathogenicies. Acta Agricultural Zhaefiangensis. 1991;3(2):61-64.

(c) 2019 Akter et al.; This is an Open Access article distributed under the terms of the Creative Commons Attribution License (http://creativecommons.org/licenses/by/4.0), which permits unrestricted use, distribution, and reproduction in any medium, provided the original work is properly cited.

Peer-review history:

The peer review history for this paper can be accessed here: http://www.sdiarticle4.com/review-history/52243 